\title{
Thermo-hydro-mechanical model of the Canister Retrieval Test is
}

\author{
M.T. Zandarin ${ }^{a}$, A. Gens ${ }^{\text {b,* }}$, S. Olivella ${ }^{\text {b }}$, E.E. Alonso ${ }^{\text {b }}$ \\ ${ }^{a}$ Universitat Politècnica de Catalunya, Barcelona, Spain \\ ${ }^{\mathrm{b}}$ Civil Engineering, Universitat Politècnica de Catalunya, Barcelona, Spain
}

\section{A R T I C L E I N F O}

Article history:

Available online 19 October 2011

\section{Keywords:}

THM modelling

Interfaces

Nuclear waste repository simulation

Bentonite

\begin{abstract}
A B S T R A C T
The paper presents a 2-D axisymmetric numerical simulation of the Canister Retrieval Test (CRT). The main objectives of this analysis are the study of the canister-buffer and buffer-host rock interfaces; and the evaluation of the mathematical models used to predict the THM behaviour of the buffer and interface. The THM simulation was performed using the finite element program Code-Bright. The constitutive law adopted to represent the mechanical behaviour of bentonite and pellets is the Barcelona Basic Model (BBM) with a non-linear elastic component accounting for swelling. A joint element with a nonlinear elastic mechanical law was implemented in the code for the simulation of the opening-closure of the interface canister-buffer. The formulation of this element also incorporates appropriate thermal and hydraulic laws. The evolution of temperatures, relative humidities and stresses recorded during the test were compared with the simulation results. Comparing the results measured in situ with the results of numerical analysis shows that the formulation used is able to reproduce satisfactorily the phenomena involved in the test as well as their interactions. In addition, the final dry density and degree of saturation measured in samples of bentonite and pellets extracted during the test dismantling were also in agreement with the calculated values.
\end{abstract}

(c) 2011 Elsevier Ltd. All rights reserved.

\section{Introduction}

The main objective of the Canister Retrieval Test (CRT) was to demonstrate that retrieval of canisters is technically feasible at any stage of the operating phase. In addition, the CRT experiment has also been used to carefully record the THM processes in the Swedish KBS-3V deposit arrangement. This makes it very suitable for modellers to investigate the formulations used in the simulations, as the calculated results can be checked against experimental data.

The CRT experiment has been numerical modelled in the context of the THERESA (Thermo-Hydrological-Mechanical-Chemical processes for application in repository safety assessment) European research project. In this paper the THM behaviour of interfaces present between canister and engineered buffer and the homogenisation of the engineer barrier formed by bentonite blocks and a pellet-filled slot are considered.

The paper starts with a description of the geometry and protocol of the Canister Retrieval Test. The THM formulation adopted to perform the simulation and the determination of materials

\footnotetext{
Submitted to 4th International Meeting 'Clays in Natural \& Engineered Barriers for Radioactive Waste Confinement', Nantes, March 29-April 1, 2010.

* Corresponding author. Address: Department of Geotechnical Engineering and Geosciences, Jordi Girona 1-3, Campus Norte, Edificio D-2, Universitat Politècnica de Catalunya, 08034 Barcelona, Spain. Fax: +34 934016867

E-mail address: antonio.gens@upc.edu (A. Gens).
}

parameters is then presented. Afterwards, the numerical results obtained from the simulation of the test are compared with the experimental data. Finally, a discussion of the results is presented followed by some conclusions.

\section{Description of Canister Retrieval Test}

The Canister Retrieval Test is a full scale in situ test heating that involved the placement of a full-scale canister in vertical drifts surrounded by an engineered barrier. A view of the experimental geometry is given in Fig. 1b extracted from Börgesson (2007).

The deposition tunnel for the experiment is located in the 420-m level of the Aspö underground laboratory and was excavated by conventional drill and blast. It has an approximately $6 \times 6 \mathrm{~m}$ horseshoe-shaped section. Two deposition boreholes were bored with a full-face tunnel boring machine modified for drilling vertical boreholes. The deposition borehole is $8.55 \mathrm{~m}$ deep and has a diameter of $1.76 \mathrm{~m}$. The surrounding rock at the upper part of the borehole consists mainly of greenstone and the lower part of Äspö diorite. One of the boreholes has been used for Canister Retrieval Test (CRT). The other borehole was used to perform the Temperature Buffer Test (TBT). The experiments, CRT and TBT, are placed approximately at the tunnel centreline. The centreto-centre distance between the two deposition boreholes is $6 \mathrm{~m}$, which is the spacing being considered for the deep repository (Fig. 1a). 
(a)

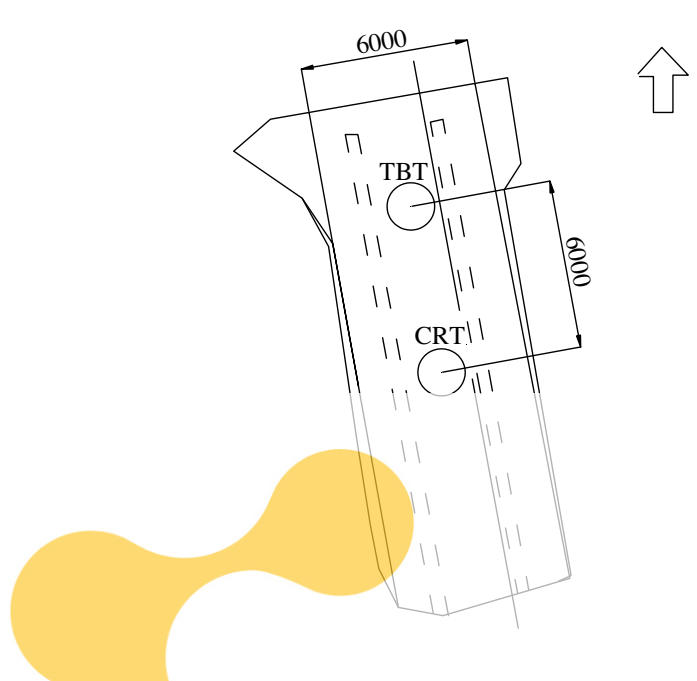

(b)

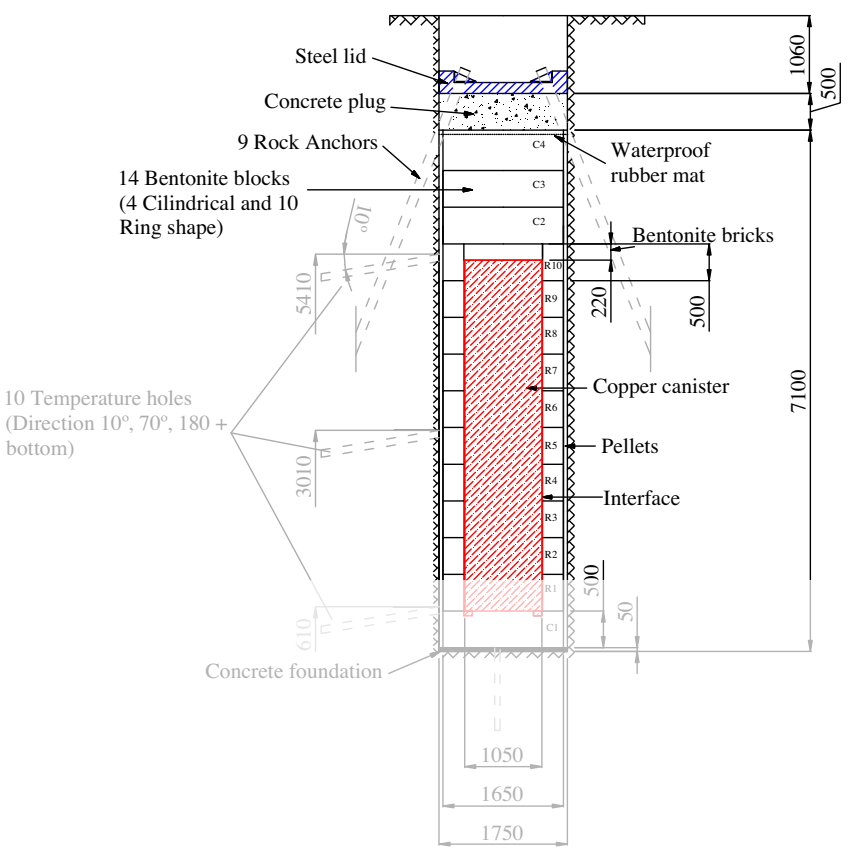

Fig. 1. (a) Location of TBT and CRT in the TASD tunnel of the Aspö underground laboratory. (b) Canister Retrieval Test geometry (Börgesson, 2007).

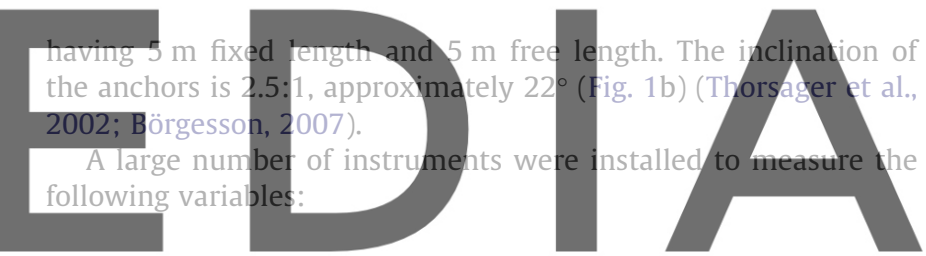
bentonite blocks and rings with an initial dry density of 1710 and $1790 \mathrm{~kg} / \mathrm{m}^{3}$, respectively. The initial water content of the bentonite was $17.3-16.7 \%$ with a mean value of $17 \%$. The bentonite buffer was installed in form of blocks and rings of bentonite. The blocks have a diameter of $1.65 \mathrm{~m}$ and a height of $0.5 \mathrm{~m}$. Ringshaped or cylindrical bentonite blocks are placed in the borehole. When the stack of blocks was $6 \mathrm{~m}$ high, the canister, equipped with electrical heaters, was lowered down in the centre of the borehole and the cables to the heaters and instruments were connected.

A canister obtained from SKB's Encapsulation Project was used in the Canister Retrieval Test. The outside diameter of the canister is $1050 \mathrm{~mm}$. The height of the canister is $4.83 \mathrm{~m}$ and the weight 21.4 tonnes.

At the top of the canister, MX-80 bentonite bricks fill up the volume between the canister top surface and the top surface of the upper ring (R10). The height difference between the two surfaces was 220-230 mm. The space between the bentonite blocks and the borehole wall is filled with bentonite pellets and water. Additional blocks were emplaced until the borehole was filled to a distance of one metre from the tunnel floor.

The top of the borehole was sealed with a retaining structure formed by a plug made of concrete, a steel lid and rock anchors. The aim of the structure is to prevent the blocks of bentonite from swelling uncontrollably.

An impermeable rubber mat was installed between bentonite block C4 and the concrete plug. On top of the plug the steel lid was installed. The plug and lid can move vertically and are attached to the rock by nine rock anchors. Each of the nine rock anchors consists of 19 steel wires with a nominal area of $98.7 \mathrm{~mm}^{2}$

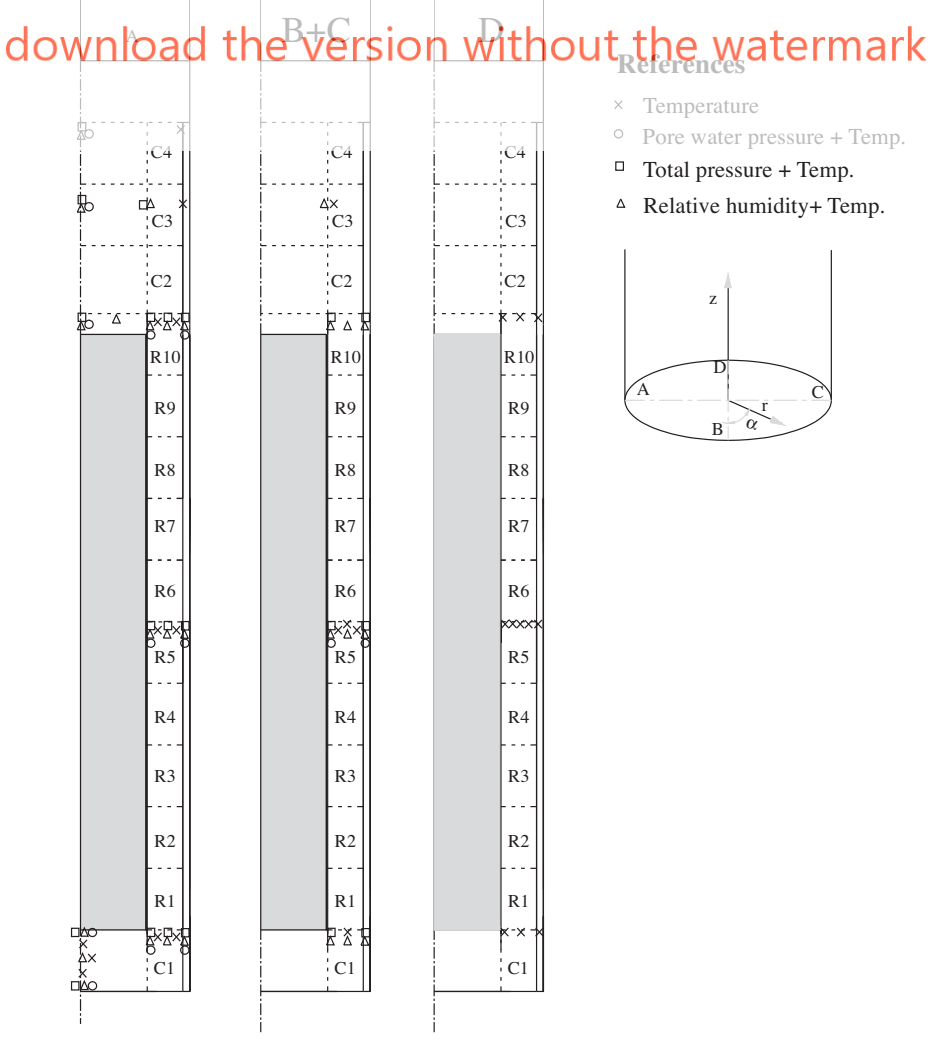

Fig. 2. Schematic view of the sensor locations in the Canister Retrieval Test (Börgesson, 2007). 


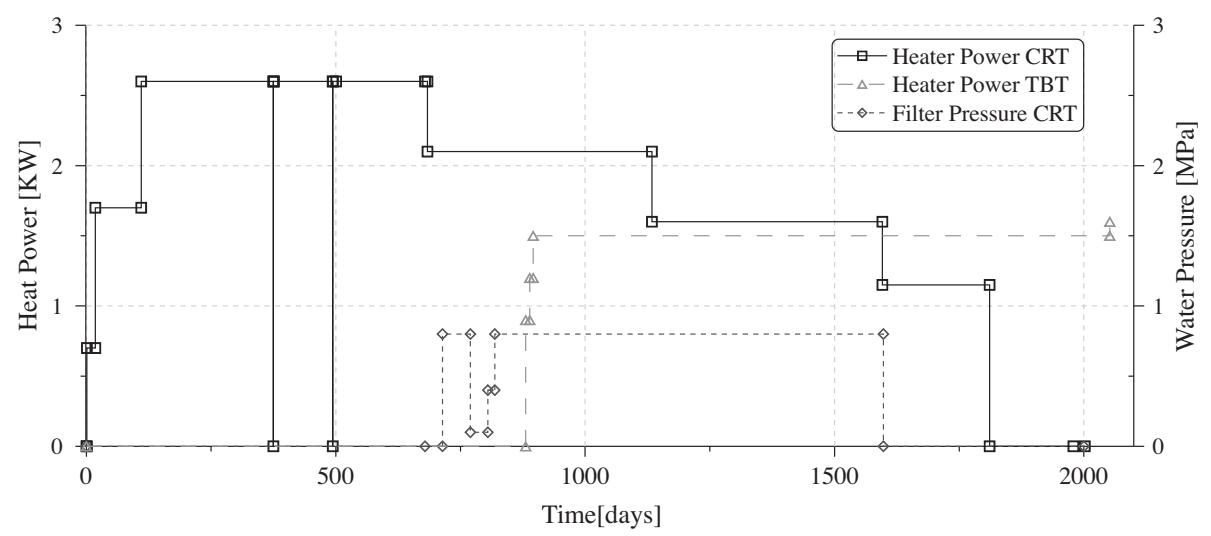

Fig. 3. Graph of the heat power protocols of CRT and TBT and the filter pressure protocol of CRT (Börgesson, 2007).

- Canister - temperature and strain.

- Rock mass - temperature and stress.

- Retaining system - force and displacement.

- Buffer - temperature, relative humidity, pore pressure and total pressure.

The instrumented sections are indicated in Fig. 2. The positions of the instrument in the buffer are indicated as follows: bentonite ring or cylinder number counted from the bottom/direction A $\left(180^{\circ}\right), \mathrm{B}\left(0^{\circ}\right), \mathrm{C}\left(270^{\circ}\right)$ or $\mathrm{D}\left(90^{\circ}\right) /$ radial distance from centre line in mm, The identification of the sensors distance in metres from the bottom/d distance in metres from the borehole Temperatures were measured using humidity was determined using Wescor psychrometers and capac-
itive transducers manufactured by Vaisala. Total pressures were recorded using Geokon transducers (Börgesson, 2007).

\section{Register for free at https//www.scipedia.com to c}

3. Test protocol

1. The starting date of the experiment was October 26, 2000 (0010-26) when the buffer-rock interface was filled with pellets. Afterwards, water was pumped into the gap and filter mats.

2. Once pellets were hydrated the concrete plug was cast and heating started. Heating began with an initially applied constant power of $700 \mathrm{~W}$ at day 1.

3. When the concrete plug rose $13 \mathrm{~mm}$ due to bentonite swelling three rock anchors were locked on day 5 . The initial force in each anchor was $20 \mathrm{kN}$.

4. The canister heating power was raised twice, at day 18 to $1700 \mathrm{~W}$ and at day 110 to $2600 \mathrm{~W}$.

5. When the total force exceeded $1500 \mathrm{kN}$, the remaining six anchors were fixed. This procedure took place on days 46-48. The total force where distributed equally between all anchors, about $170 \mathrm{kN} / \mathrm{anchor}$.

6. The water pressure at filter mats was increased gradually up to $0.8 \mathrm{MPa}$ from day 679 to 714 (02-09-05 to 02-10-10). On day 770 the water pressure was decreased to $0.1 \mathrm{MPa}$. Then it was increased again up to $0.8 \mathrm{MPa}$ on day 819 (03-01-23) and remained constant until day 1598 (05-03-12), then the water pressure was removed.

7. Heating of TBT was started at day 881 (03-03-26). This heating affected sightly the temperature of the CRT buffer.

8. The heating was switched of on day 1811 (05-10-11). After the end of test, several samples from the buffer were drilled to measure their dry density and degree of saturation. (Börgesson, 2007)
Fig. 3 shows a summary of the heat power and filter pressure protocol followed in the CRT and TBT tests.

\section{Features of the analysis and material parameters}

The analysis has assumed axisymmetric conditions using the mesh shown in Fig. 4. The materials considered in the model are bentonite, discriminating between cylinders, rings and bricks; pel-

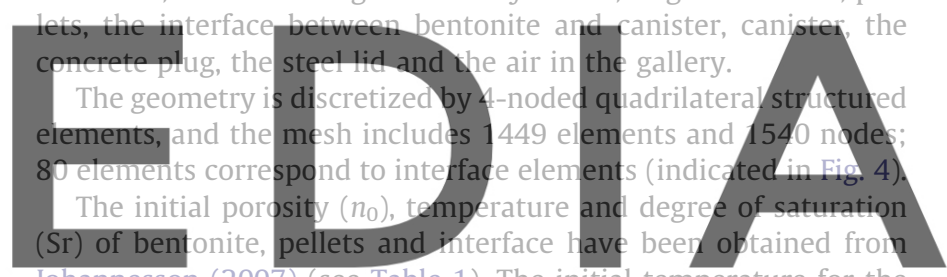
Johannesson (2007) (see Table 1). The initial temperature for the air gallery is equal $15^{\circ} \mathrm{C}$ and for the other materials are $20^{\circ} \mathrm{C}$
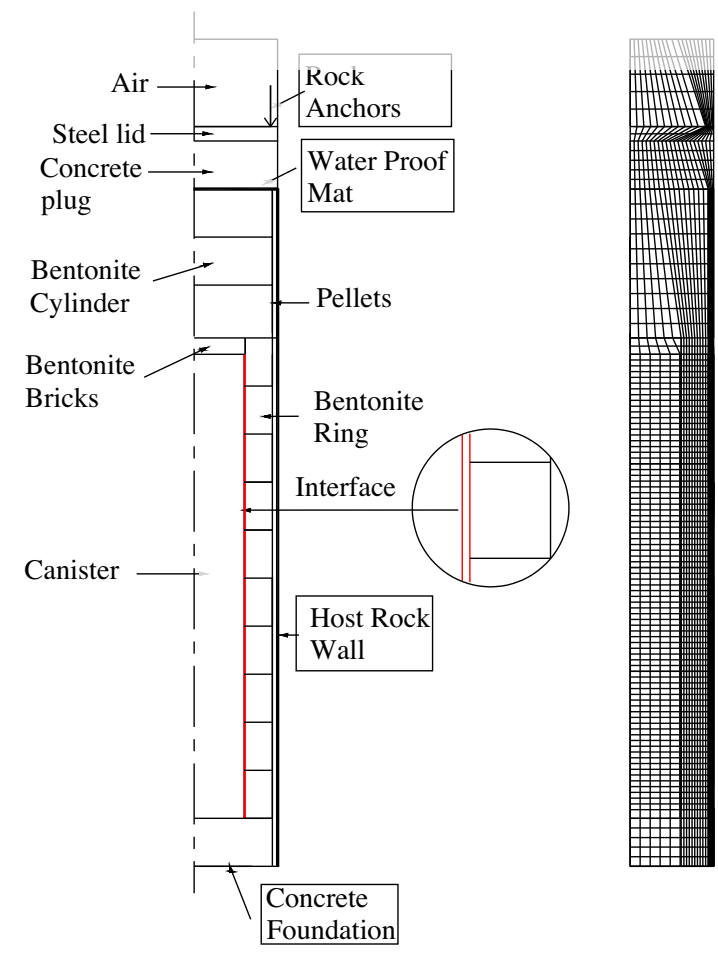

Fig. 4. Geometry and materials of CRT considered for the numerical model and finite element mesh used for discretization. 


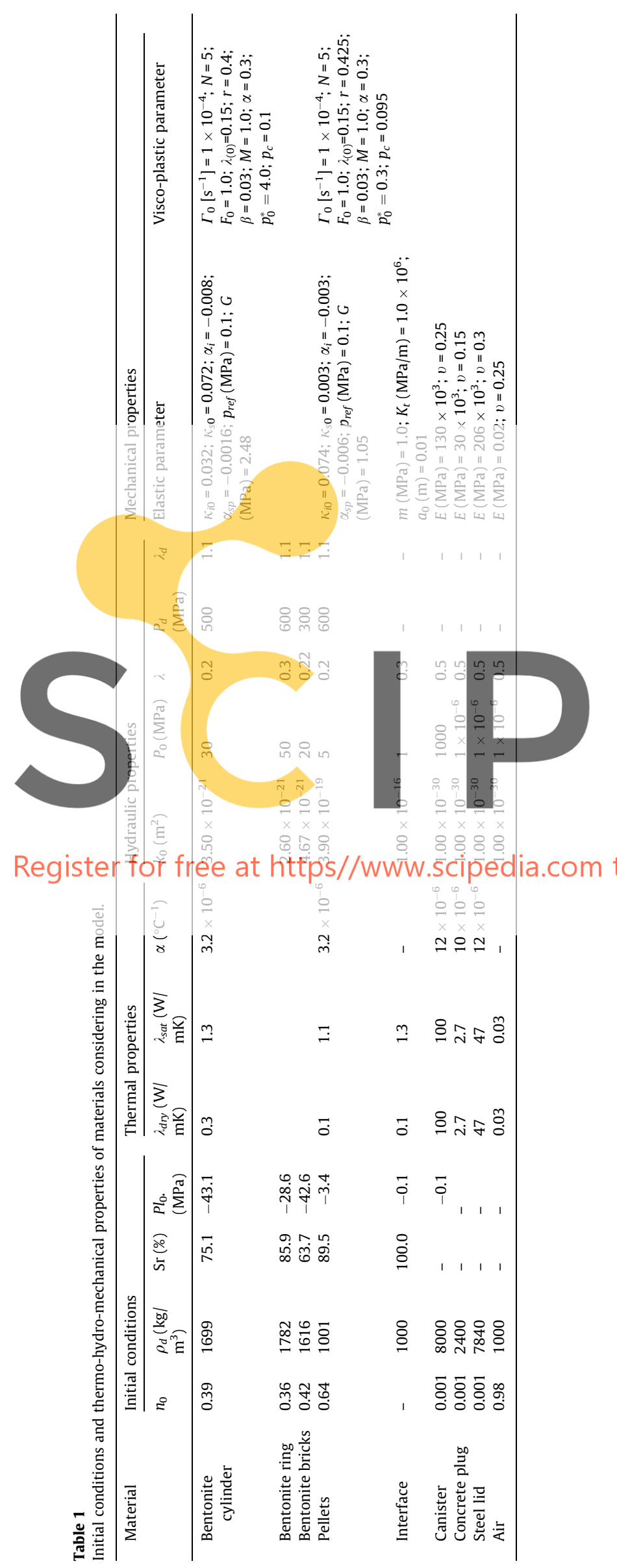

(The difference between temperatures is due to the gallery ventilation). The initial liquid pressures $\left(P l_{0}\right)$ were calculated considering the retention curves of the materials and their saturation degrees as measured in the tests. The retention curve obtained from the laboratory tests were fitted with the model proposed by Sánchez (2004), see Fig. 7. Initial total stress of the materials is assumed isotropic and equal to $0.11 \mathrm{MPa}$. A constant gas pressure equal to atmospheric was assumed throughout the test. The initial conditions of the materials are summarised in Table 1.

The heater power was applied over the canister volume according to the test protocol without considering the falls of heat power to zero on days 375 and 494 (Fig. 3). A special boundary condition was prescribed in the host rock to allow some energy flux. The energy flux is expressed as an outflow rate given by:

$j_{e}=j_{e}^{0}+\gamma_{e}\left(T^{0}-T\right)+E_{g}^{w}\left(j_{g}^{w}\right)+E_{l}^{w}\left(j_{l}^{w}\right)$

where $\gamma_{e}$ is a leakage coefficient. This parameter was calibrated to obtain the temperature measured by sensors at the host rock wall. Also, this boundary condition allows considering the influence of the heating from the TBT experiment.

The filter pressures shown in Fig. 3 were applied at the host rock wall. The bottom boundary of the Cylinder 1 and the top of Cylinder 4 were considered impervious because of the presence of concrete foundation and a rubber mat respectively.

The force applied on the steel lid by the anchors was considered as point load acting on the steel lid (Fig. 4). The point load was calculated from the total force measured in the steel lid $(1500 \mathrm{kN})$.
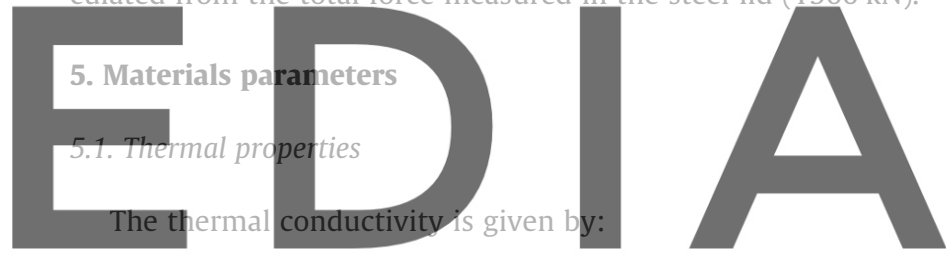

$\lambda=\lambda_{\text {sat }} \sqrt{S_{l}}+\lambda_{\text {dry }}\left(1-\sqrt{S_{l}}\right)$
$S_{I}=1$ and $\lambda_{d r y}$ is the thermal conductivity for a $S_{I}=0$.

The parameters $\lambda_{\text {sat }}$ and $\lambda_{\text {dry }}$ for bentonite and pellets were determined fitting the experimental data with Eq. (2) (Fig. 5a and b). The thermal conductivities of canister, concrete plug and steel lid were given in Börgesson et al. $(1994,1995)$ and Sugita et al. (2003). For the interface, the conductivities adopted were similar to those of bentonite, because during the test the bentonite expands filling the interface space. Also the specific energy of the solid phase and the thermal expansion coefficients of bentonite, pellets are given in Börgesson et al. (1995). The properties for canister, concrete plug and steel lid were given in Börgesson (2007). The thermal parameters are listed in Table 1.

\subsection{Hydraulic properties}

The hydraulic conductivity of the materials is given by:

$\mathbf{K}_{l}=\frac{\mathbf{k} k_{r l} \rho_{l} g}{\mu_{l}}$

where $k$ is the intrinsic permeability; $k_{r l}$ is the relative permeability; $\rho_{l}$ is the liquid density; $\mu_{l}$ is the viscosity of the liquid and $g$ is the gravitational force.

The intrinsic permeability depends on porosity according to:

$\mathbf{k}=k_{0} \frac{n^{3}}{(1-n)^{2}} \frac{\left(1-n_{0}\right)^{2}}{n_{0}^{3}} \mathbf{I}$

where $k_{0}$ is the reference intrinsic permeability at the reference porosity $n_{0}$. 
(a) Bentonite

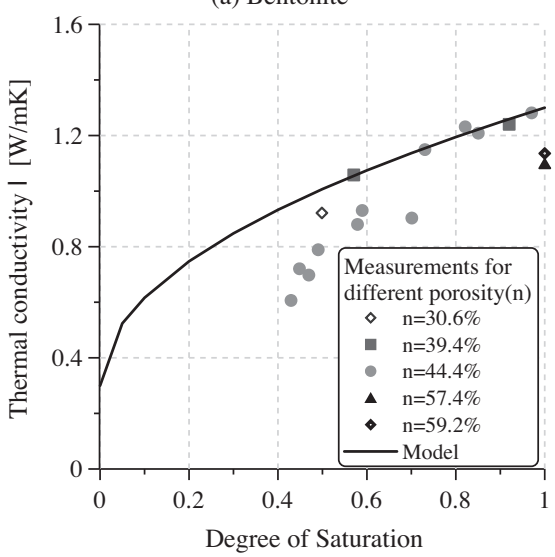

(b) Pellets

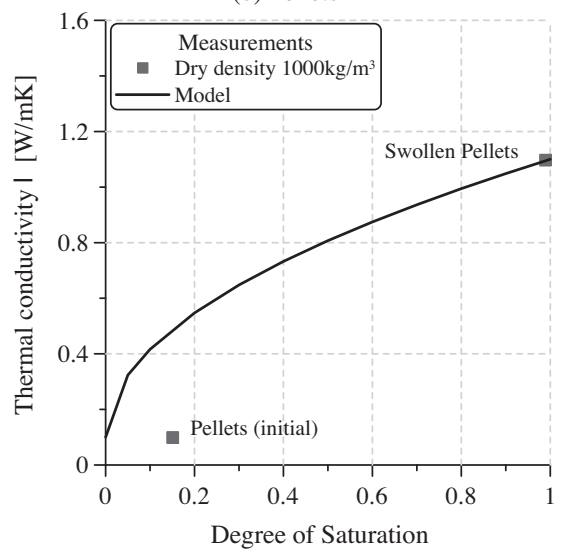

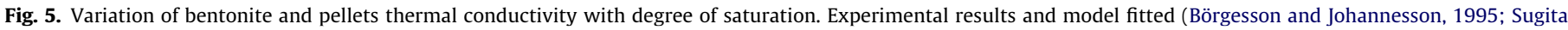
et al., 2003).

The intrinsic permeabilities at different porosity of MX-80 bentonite and pellets were experimental measured by Pusch (2001), Villar (2002, 2003), Börgesson and Hernelind (1999), Imbert et al. (2004) and Lajudie et al. (1994). Fig. 6 shows the values of intrinsic permeabilities adopted for bentonite cylinders, rings, bricks and pellets. For the interface element, a constant permeability five orders of magnitude higher than bentonite was adopted. This greater permeability was considered adequate to model the high conductivity or the interface that has a thicknes For the canister, steel lid and air pared to bentonite permeabilities we

The lative humidity of the liquid pha

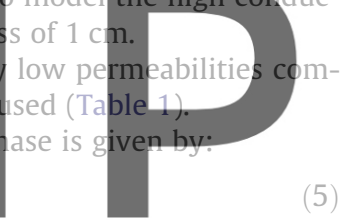

where $S_{e l}$ is the effective degree of saturation and $n$ is a parameter of

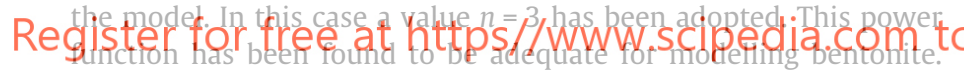
This function and value of $n$ were determined from back-calculation of hydration tests on bentonite (Pintado et al., 2002). The effective degree of saturation is evaluated as:

$S_{e l}=\frac{S_{l}-S_{l r}}{S_{l s}-S_{l r}}$

where $S_{l r}$ is the residual saturation; $S_{l s}$ is the maximum saturation and $S_{l}$ is the liquid degree of saturation which is calculated by the retention curve.
The retention curve adopted in the analysis for MX-80 bentonite and pellets is a modification of the Van Genutchen expression (1978) proposed by Sánchez (2004).

$S_{l}=\left[1+\left(\frac{\psi}{P}\right)^{\frac{1}{1-\lambda}}\right]^{-\lambda} f_{d} \quad f_{d}=\left(1-\frac{\psi}{P_{d}}\right)^{\lambda_{d}}$

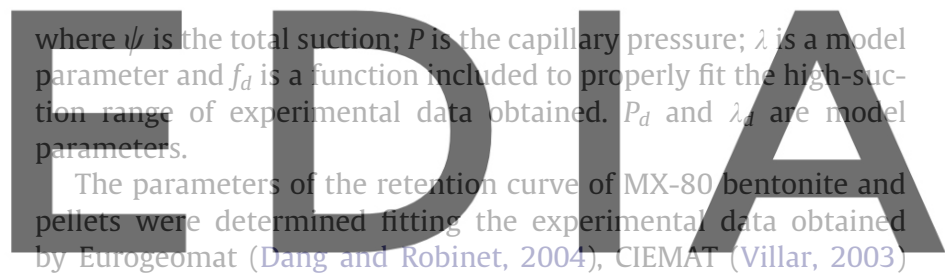
and Clay Technology (Hökmark and Fälth, 2003) (Fig. 7 and Table

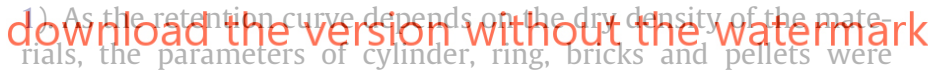
determined considering their dry density values (Fig. 7).

For the rest of materials, the original expression proposed by Van Genuchten (1978) was used:

$S_{l}=\left[1+\left(\frac{\psi}{P}\right)^{\frac{1}{1-\lambda}}\right]^{-\lambda}$

As the permeability for the interface element was adopted higher than for the bentonite, a low value of $P$ was adopted for the

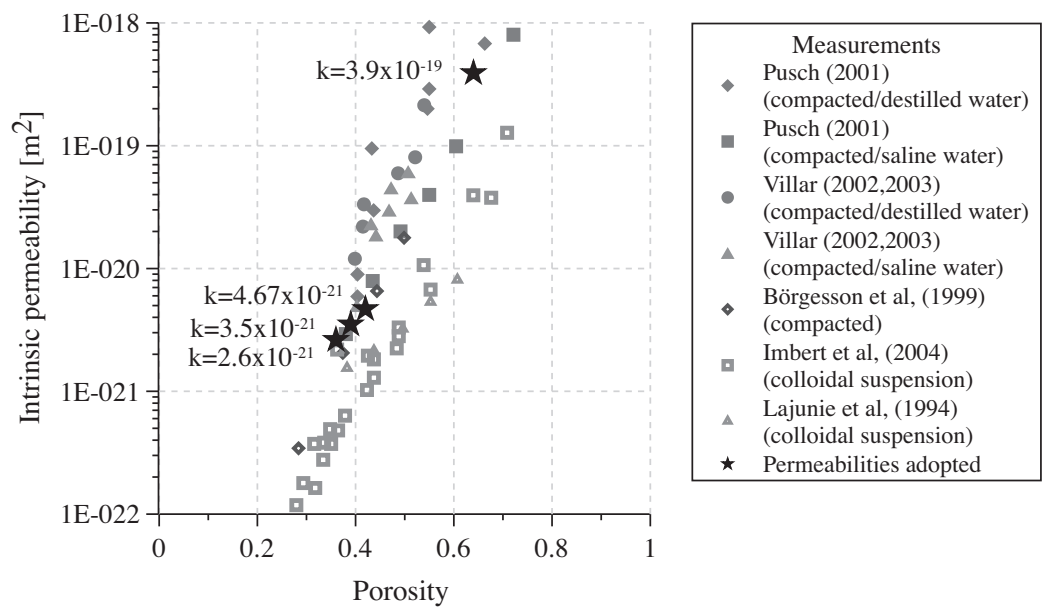

Fig. 6. Variation of intrinsic permeability with porosity for MX-80 bentonite. Experimental results and values adopted. 
(a) Bentonite Cylinder

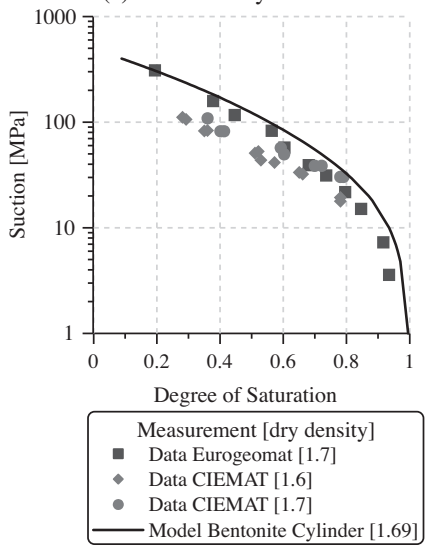

(b) Bentonite Ring

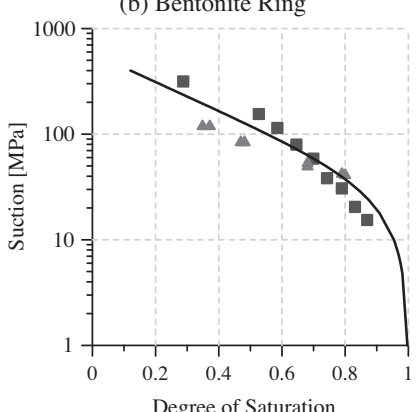

Measurements [dry density]

- Data Eurogeomat $[2.0]$

- Data CIEMAT [1.8]

- Model Bentonite Ring [1.78] (c) Bentonite Bricks

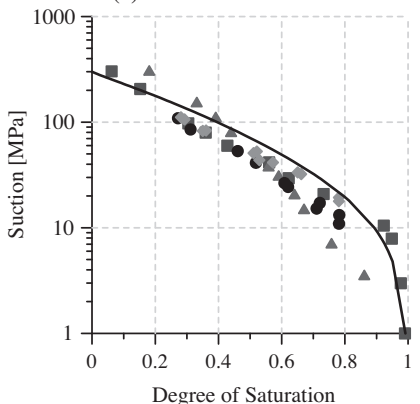

Degree of Saturation

Measurements [dry density]

Data Eurogeomat [1.4]

- Data CIEMAT [1.6]

- Data Clay Technology [1.6]

Model Bentonite Bricks [1.61] (d) Pellets

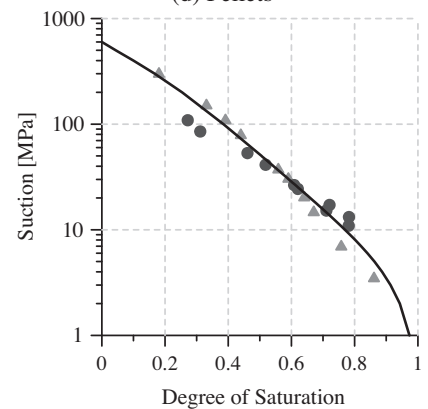

Measurements [dry density]

$\Delta$ Data Eurogeomat [1.4]

- Data CIEMAT [1.5] - Model Pellets [1.57]

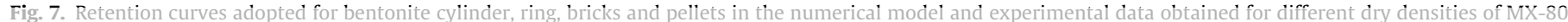
bentonite. Data provided by Eurogeomat were found in Dang and Robinet (2004), by Clay Technology in Hökmark and Fälth (2003) and by CIEMAT in Villar (2003).

interface element in order to allow a fast drying of those elements (see Fig. 8). The values used for canister, concrete and steel lid did formulation considered porous medium it is necessary to assume these values to run the analyses.

The hydraulic parameters of the materials are summarised in
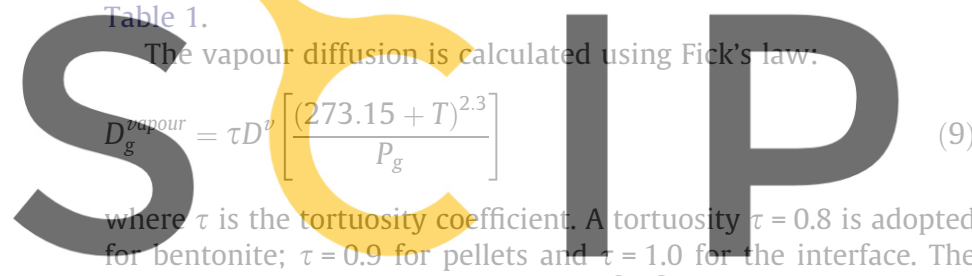

coefficient of diffusion, $D^{v}$, is $5.9 \times 10^{-6} \mathrm{~m}^{2} / \mathrm{s} / \mathrm{K}$ not affect the hydraulic behaviour of the model. As the numerical

where $\varepsilon_{v}^{e}$ and $\varepsilon_{s}^{e}$ are the volumetric and deviatoric components of the elastic strain respectively; $\kappa_{i}$ and $\kappa_{s}$ are the elastic stiffness for changes in net mean stress and suction respectively; $p^{\prime}$ is the mean net stress; $\psi$ is the suction; $e$ is the void ratio, $J$ is the square root of the second invariant of deviatoric stress tensor $\left(J=\frac{1}{2} \operatorname{trace}(\mathbf{s}: \mathbf{s})=\frac{1}{3} q^{2} ; \mathbf{s}=\sigma^{\prime}-p^{\prime} \mathbf{I}\right) ; G$ is the shear modulus.

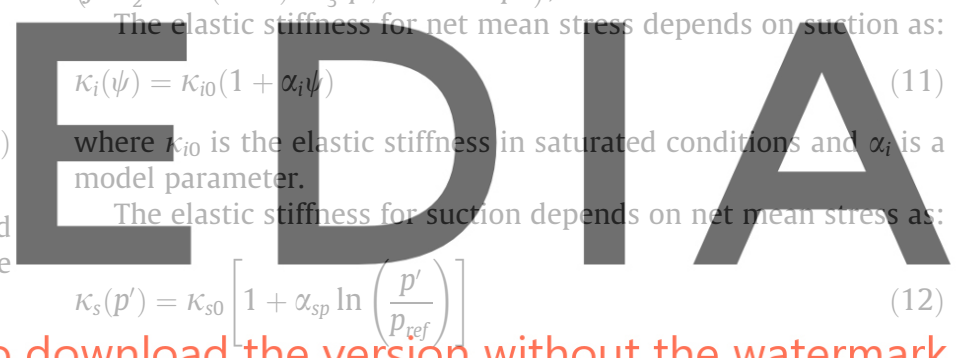

download the version without the watermark where $\kappa_{s 0}$ and $\alpha_{s p}$ are model parameters; and $p_{\text {ref }}$ is the pressure reference.

The viscoplastic strains $\left(\dot{\varepsilon}^{v p}\right)$ are calculated as:

The mechanical constitutive model adopted for MX-80 bentonite and pellets is a modified form of the Barcelona Basic Model; BBM (Alonso et al., 1990). The total strain of the model is calculated adding elastic and viscoplastic strains. The original elastic formulation of BBM is modified to reproduce the expansive behaviour of the bentonite. The elastic model adopted here is:

$\dot{\varepsilon}_{v}^{e}=\frac{\kappa_{i}(\psi)}{1+e} \frac{\dot{p}^{\prime}}{p^{\prime}}+\frac{\kappa_{s}\left(p^{\prime}\right)}{1+e} \frac{\dot{\psi}}{\psi+p_{a t}} \quad \dot{\varepsilon}_{s}^{e}=\frac{j}{G}$

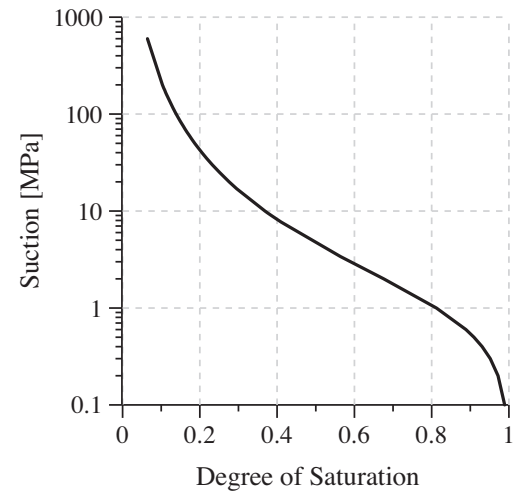

Fig. 8. Retention curve adopted for the interface between canister and bentonite ring. $\dot{\varepsilon}^{v p}=\Gamma\langle\Phi(F)\rangle \frac{\partial G}{\partial \sigma^{\prime}} ; \quad \Phi(F)=\left(\frac{F}{F_{0}}\right)^{N}$

where $\gamma$ is the viscosity; $N$ is the power of stress; $F_{0}$ is a value of reference; $F$ is the yield surface and $G$ is the viscoplastic potential.

The yield surface is defined by:

$F=3 J^{2}-M^{2}\left(p^{\prime}+p_{s}\right)\left(p_{0}-p^{\prime}\right)=0$

And the viscoplastic potential by:

$G=3 J^{2}-\alpha M^{2}\left(p^{\prime}+p_{s}\right)\left(p_{0}-p^{\prime}\right)=0$

where $M$ is the slope of the critical state; $p_{0}$ is the apparent unsaturated preconsolidation pressure; $p_{s}$ considers de dependency of shear strength with suction and $\alpha$ is a model parameter that makes the model non-associated.

The apparent unsaturated preconsolidation $\left(p_{0}\right)$, the variation of compressibility $(\lambda(\psi))$ with suction and the hardening law were calculated according the expression proposed by Alonso et al. (1990).

The elastic stiffness $\kappa_{i 0}$ and $\alpha_{i}$; and the parameters of compressibility $\lambda(0) r$ and $\beta$ for MX-80 bentonite were determined fitting the experimental data obtained by Tang (2005) and Villar (2005) (see Fig. 9). The other parameters were determined from back calculation. The parameters for the pellets were determined based on experimental values obtained by Hoffman et al. (2007). 

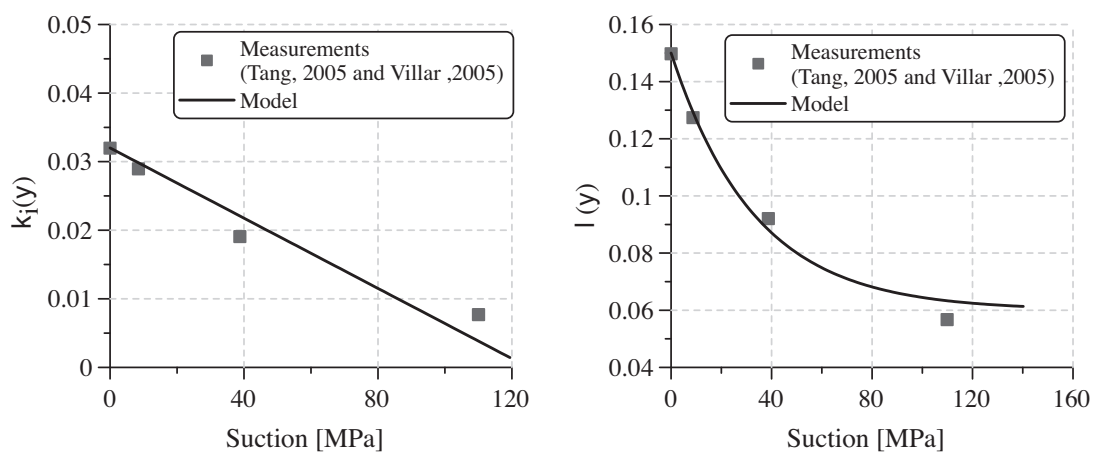

Fig. 9. (a) Variation of MX-80 bentonite elastic stiffness with suction. (b) Variation of compressibility with suction (Tang, 2005; Villar, 2005).

\subsubsection{Interface elements}

The mechanical behaviour of the interface elements is defined by the relationship between stress and relative displacements in the mid-plane of the interface element (Fig. 10). The stress tensor of the mid-plane is calculated by:

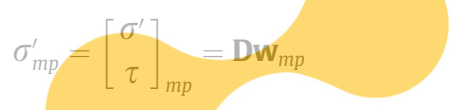

where $\sigma_{m p}^{\prime}$ is the net effective stress of the mid-plane of the element and it is defined as $\sigma_{m p}^{\prime}=\sigma_{m p}-\max \left\{P g ; P l_{m p}\right\} ;(m p$ is the total mean stress of the micl-plane; $\sigma$ is total mean stress; $P_{g}$ is the gas pressure



Where $u_{n}$ and $u_{s}$ are the normal and tangential relative displace-

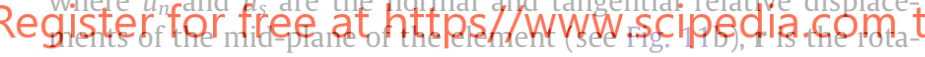

tion matrix that transforms the relative displacements in the local orthogonal coordinate system to the global coordinate system. $\mathbf{N}_{m p}^{u}$ is a matrix of shape functions, $\mathbf{I}_{4}$ is a identity matrix of 4 th order and $u_{e}$ is the vector of the nodes element displacement.

The stiffness matrix of the interface relates the normal effective $\left(\sigma^{\prime}\right)$ and the tangential stresses $(\tau)$ with the normal $\left(u_{n}\right)$ and the tangential $\left(u_{s}\right)$ displacement of the interface element using normal $\left(K_{n}\right)$ and tangential stiffnesses $\left(K_{s}\right)$, respectively. The normal stiffness depends on the opening of the interface as shown in Eq. (21) (Gens et al., 1990) (see Fig. 10c).

$$
\left\{\begin{array}{c}
\sigma^{\prime} \\
\tau
\end{array}\right\}=\left[\begin{array}{cc}
K_{n} & 0 \\
0 & K_{s}
\end{array}\right]\left\{\begin{array}{l}
u_{n} \\
u_{s}
\end{array}\right\} \quad K_{n}=\frac{m}{a-a_{\min }}
$$

where $m$ is a parameter of the model; $a$ is the opening of the element and $a_{\min }$ is the minimum opening of the element (at this opening the element is considered closed).
A linear elastic behaviour was assumed for canister, concrete plug and steel lid and their parameters were given in Börgesson (2007)

The mechanical parameters are listed in Table 1.

\section{Test observations and model results}

In this section test observations (Goudarzi et al., 2006) are compared with the predictions of the numerical analysis.

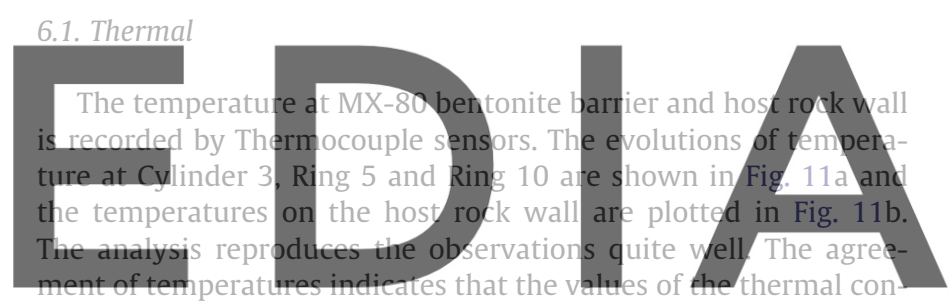

ductivities of the materials, particularly in the interface, are well

\section{downturediond the version without the watermark}

\subsection{Hydraulic}

Fig. $12 \mathrm{a}-\mathrm{c}$ shows the variation with time of relative humidity measured by capacitive sensors. The relative humidity from the numerical simulation is calculated using Kelvińs equation:

$R H=\exp \left[\frac{\psi M_{w}}{R(273+T) \rho_{l}}\right]$

where $\psi$ is the total suction; $M_{w}$ is the molecular weight of water; $R$ is the ideal gas constant, $T$ is the temperature and $\rho_{l}$ is the liquid density.

In the cooler section of the barrier (Cylinder 3 ) and in the bentonite close to the host rock wall (sensors W137, W142, W119 and W120) a monotonic increase of relative humidity is recorded. This is due to the condensation of the vapour coming from the heated (a)



(b)

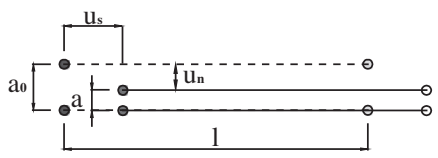

(c)

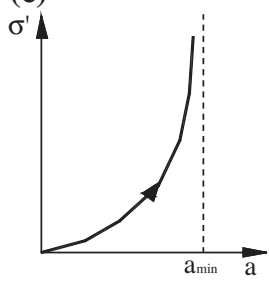

Fig. 10. Interface element with double nodes. (a) Stress state at the mid-plane of the interface element. (b) Relative displacement defined at mid-plane. (c) Elastic constitutive law of interface elements. Normal stiffness depends on interface opening. 


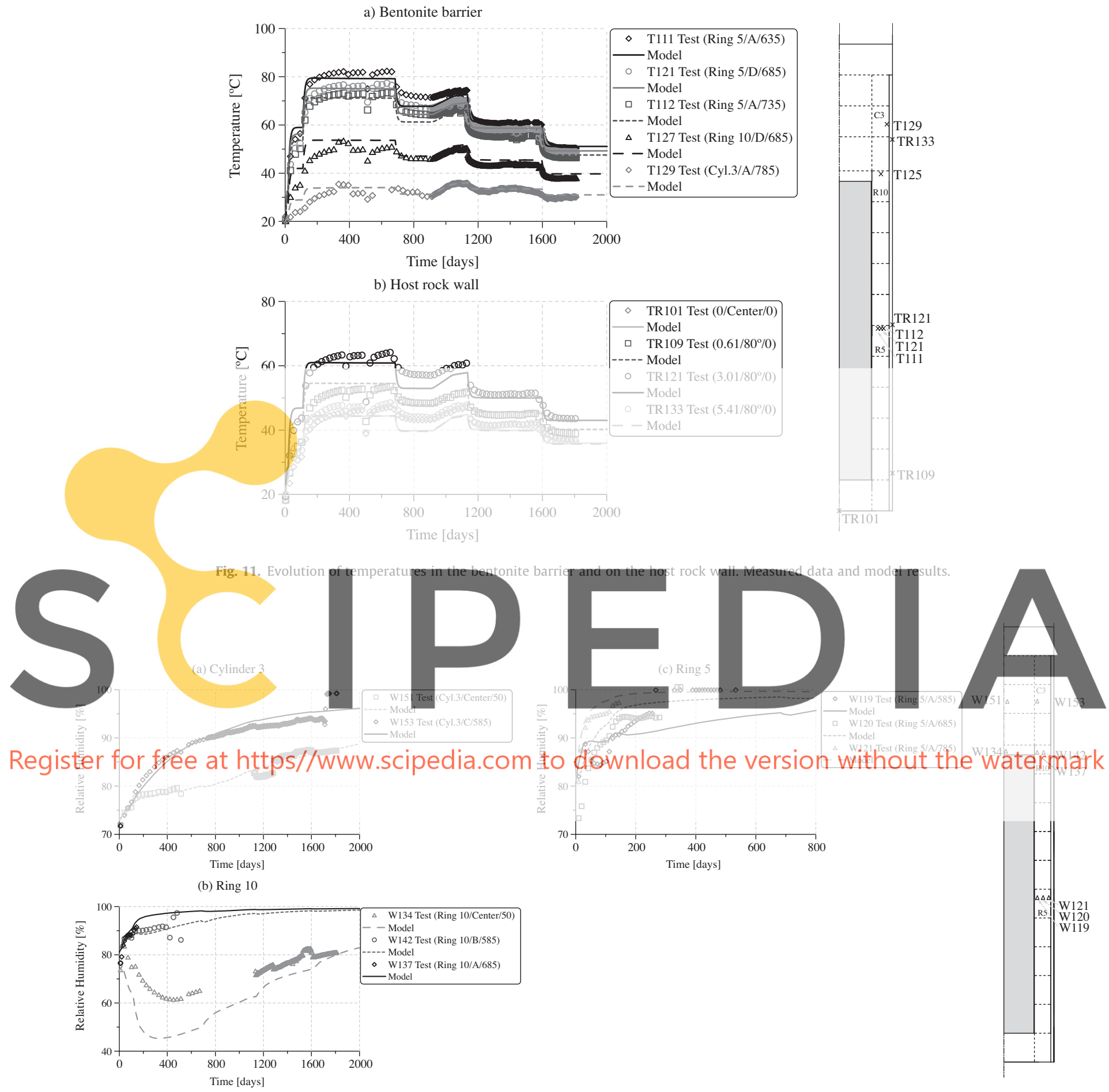

Fig. 12. Evolution of relative humidity in bentonite barrier. (a) Cylinder 3, (b) Ring 10, and (c) Ring 5. Test observations and numerical results.

zones, to the water inflow from the rock and to the artificial hydration from filter mats (Fig. 12a).

However the bentonite barrier closer to the canister exhibits an increase of relative humidity due to the vapour front driven by heating. Then the barrier dries because of the evaporation caused by the increment of the temperature. And finally, the barrier hydrates and its relative humidity increases due to the water inflow from the filter mats and rock (sensor W134 - Ring 10) (Fig. 12b). Nevertheless, at Ring 5, the drying is followed by a fast increment of relative humidity. This may be attributed to the presence of water in the interface (see Fig. 12c - sensor W119). This water is in form of vapour and hydrates the barrier. In general, the predictions from the numerical model are quite satisfactory.

The evolutions of suction measured with psychrometers and the calculated values are plotted in Fig. 13. There is not a good match between experimental and calculated results; however the decreasing trend of suction with the increment of water content of the buffer is predicted. The suction calculated decreased throughout the test; in contrast, the suctions measured kept 

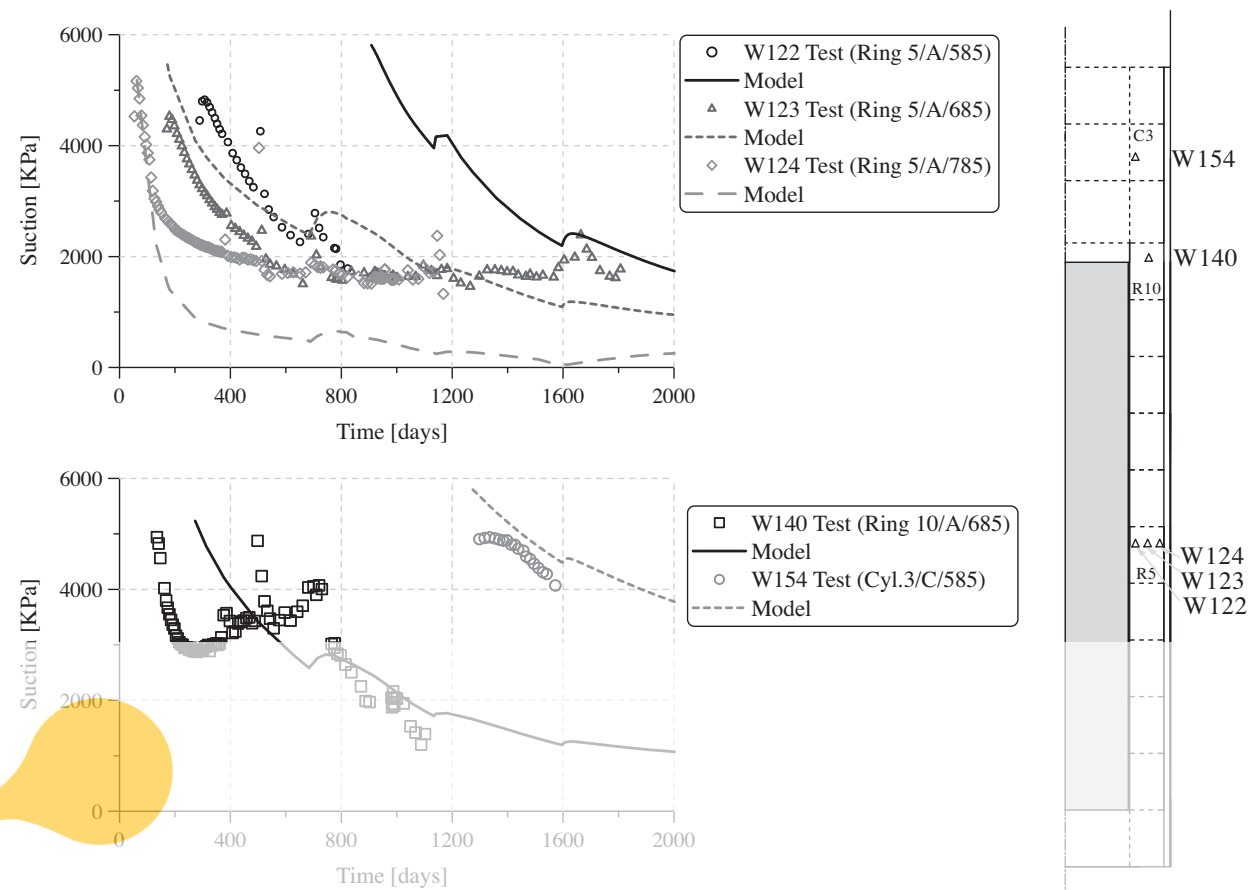

Fig. 13. Evolution of suction in bentonite barrier Ring 5, Ring 10 and Cylinder 3. Test observations and numerical results


Register for free at https\& www.scipedia.con to download the version without the watermark
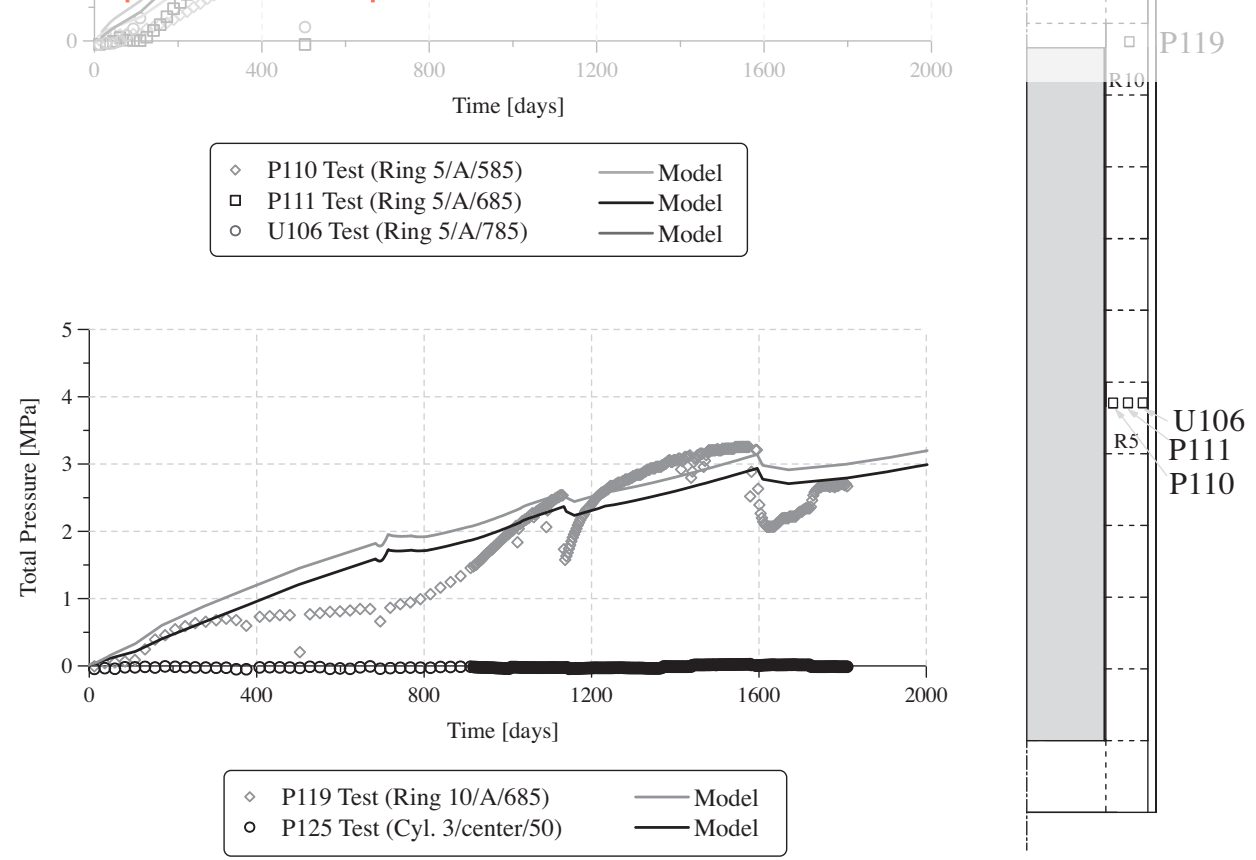

Fig. 14. Evolution of total pressure in the bentonite barrier. Experimental data and numerical results.

constant at $2 \mathrm{MPa}$ from day 800 up to the test end, perhaps due to osmotic effects not considered in the analysis. Considering osmotic effects would require the incorporation of chemical variables in the formulation (Gens, 2010). 

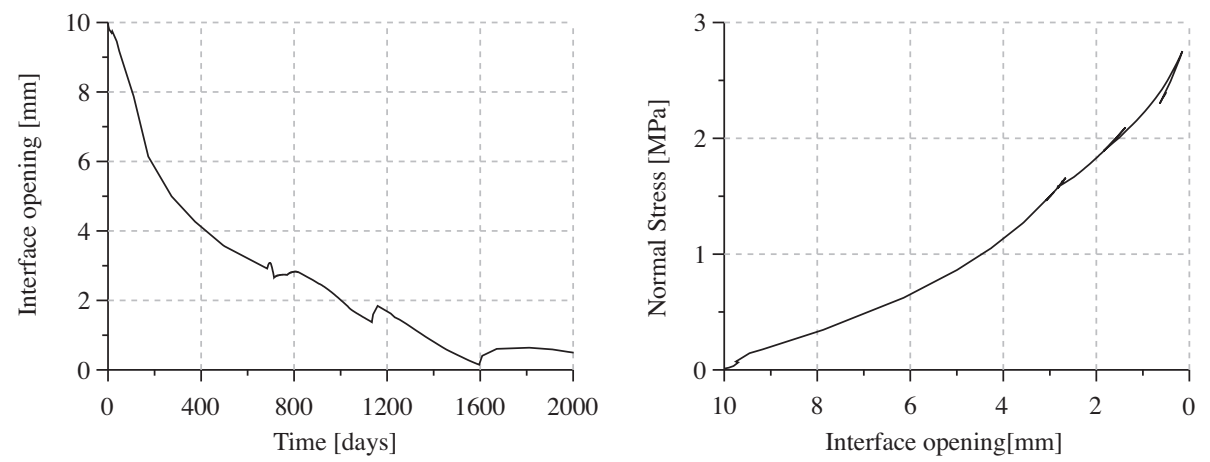

Fig. 15. Evolution of opening and normal stress of the interface between canister and bentonite barrier.

\subsection{Mechanical}

The total vertical pressure (vertical stress) for the bentonite barrier is plotted in Fig. 14. The swelling of bentonite causes stress increases up to 3.0-4.5 $\mathrm{MPa}$. The numerical results underestimated the magnitude of the stresses but follow their trend. The results could probably be improved would improve using a mechanical model that considers the double structure of expansive clays (Sánchez and Gens, 2006).

In Fig. 15 the evolutions of the opening and of the normal stress of the interface are shown. The interface closes and its stress increases as the bentonite swells. The final opening of the slot is approximately $2 \mathrm{~mm}$ and the maximum nornal stress is $2.5 \mathrm{MPa}$ corresponding to the stress calculated in the bentonite barrier next to the slot (Fig. 14 - radial distance $585 \mathrm{~mm}$ ) dismantling

After test dismantling, samples at selected sections were cored

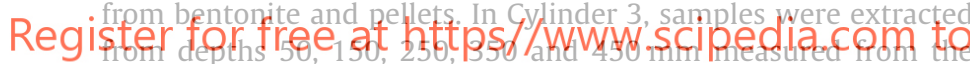

(a) Cylinder 3


(b) Ring 10
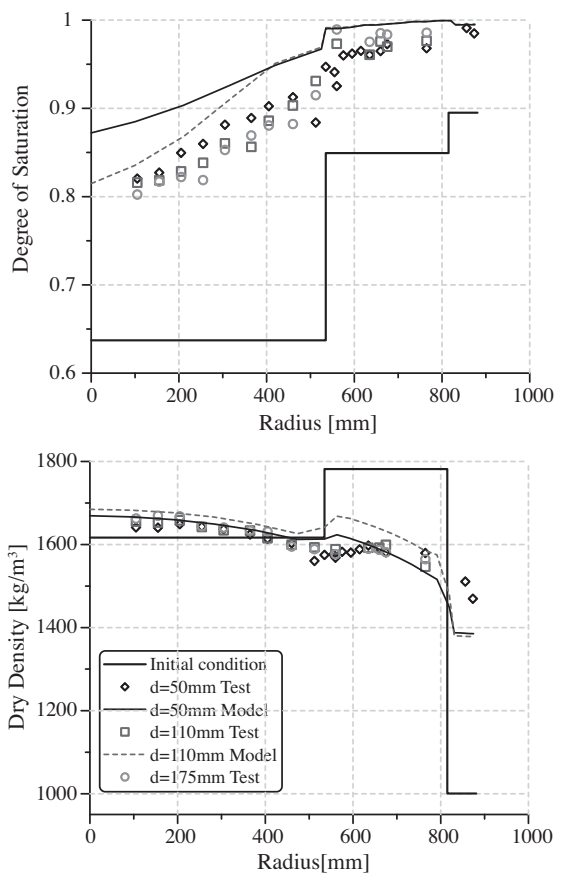

top of the block. In Ring 10, samples were extracted at depths of 50,110 and $175 \mathrm{~mm}$. At Ring 6, samples were taken from a denth of $50 \mathrm{~mm}$ and directions $\alpha=45^{\circ}, 135^{\circ}, 225^{\circ}, 315^{\circ}$ (see Fig. 2). The dry density and water content of samples were measured in the laboratory and the corresponding degree of saturation was calculated (Johannesson, 2007). The values of degree of saturation and dry density for (a) Cylinder 3, (b) Ring 10, and (c) Ring 6 are shown in Fig. 16.

In the figures, the final degree of saturation throughout the bentonite barrier is higher than the initial one even in the zone close to the canister. The degree of saturation is higher near the host rock
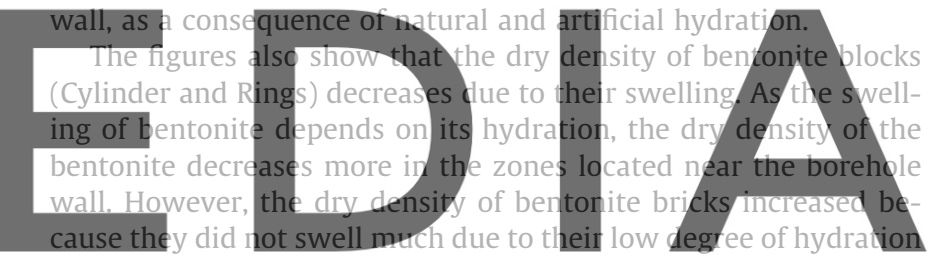

and compressed when the bentonite rings swelled. Also the bentonite swelling caused the compaction of pellets and, conse-

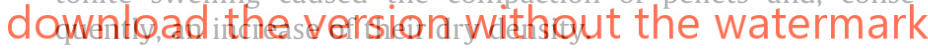

Fig. 16. Degree of saturation and dry density of Cylinder 3, Ring 10 and Ring 6 after test dismantling. Experimental and model results. 


\section{Conclusions}

A coupled THM numerical simulation of borehole disposal scheme for nuclear waste has been performed satisfactorily. The required material parameters have been mostly determined using data from laboratory tests; others were estimated from back analysis.

To model the interface between canister and bentonite a specific mechanical formulation of this element was implemented in Code-Bright. The mechanical formulation is expressed at the mid-plane of the element and relates the relative displacements of the mid-plane with the normal and tangential stress through normal and shear stiffness respectively. In particular, a normal stiffness dependent on interface opening allows the capture of non-linear behaviour under normal stress. Hydraulic and thermal behaviour were modelled in accordance with Darcýs and Fickss laws, respectively. The parameters of the interface were fitted by back calculation.

The comparison of the results measured in situ with the results of numerical analysis shows that the formulation used is able to reproduce satisfactorily the phenomena involved in the test as well as their interactions. Moreover, the model has been able to capture the final state of the bentonite and pellets showing the high degree of homogenisation of their dry density achieved during the test. Nevertheless, the magnitude of suction and total stresses would improve incorporating chemical effects in the formulation and adopting a mechanical model which considered the double structure of expansive clays.

Also, it has been possible to verify from the results that the model implemented for interfaces is able to simulate satisfactorily interface behaviour. The evolution of its opening and stress development is mainly controlled by the progress of bentonite swelling.

\section{References}

Alonso, E.E., Gens, A., Josa, A., 1990. A constitutive model for partially saturated soils. Geotechnique 40 (3), 405-430.

Börgesson, L., 2007. Canister Retrieval Test, Compilation Made for the EBS Task Force.

Börgesson, L., Hernelind, J., 1999. Coupled Thermo-Hydro-Mechanical Calculations of the Water Saturation Phase of a KBS-3 Deposition Hole, Technical Report TR99-41.

Börgesson, L., Johannesson, L.-E., Sandén, T., Hernelind, J., 1995. Modelling of the Physical Behaviour of Water Saturated Clay Barriers. Laboratory Tests, Material Models and Finite Element Application, SKB Technical Report 95-20.

Börgesson, L., Johannesson, L.-E., 1995. Thermo-Hydro-Mechanical Modelling of Water Unsaturated Buffer Material, SKB Work Report 95-32.
Börgesson, L., Fredrikson, A., Johannesson, L.-E., 1994. Heat Conductivity of Buffer Materials, SKB Technical Report 94-29.

Dang, K.D., Robinet, J.-C., 2004. Thermo-Hydro-Mechanical Behaviour of MX80 Bentonite for Temperature $\geqslant 100{ }^{\circ} \mathrm{C}$. Final Report. ANDRA Report C.RP.0EUG.02.008.

Gens, A., 2010. Soil-environment interactions in geotechnical engineering. 47th Rankine Lecture. Geotechnique 60 (1), 3-74.

Gens, A., Carol, I., Alonso, E.E., 1990. A constitutive model for rock joints; formulation and numerical implementation. Comput. Geotech. 9, 3-20.

Goudarzi, R., Börgesson, L., Röshoff, K., Edelman, M., 2006. Sensors Data Report (Period: 001026-060501) Canister Retrieval Test, Report No. 12.

Hoffman, C., Alonso, E.E., Romero, E., 2007. Hydro-mechanical behaviour of bentonite pellet mixtures. Phys. Chem. Earth 32, 832-849.

Hökmark, H., Fälth, B., 2003. Temperature Buffer Test. Predictive Modelling Programme. Äspö Hard Rock Laboratory Internal Report F12.1G 1012125.

Imbert, C., Billaud, P., Touze, G., Dang, K.D., 2004. Comportement thermo-hydromécanique d'une argile gonflante méthodologique en situation de stockage. CEA, Rapport RT-DPC/SCCME 04-677-A.

Johannesson, L.E., 2007. Dismantling and sampling of the buffer and determination of density and water ratio. International Progress Report IPR-07-16, SKB, Stockholm, Sweden.

Lajudie, A., Raynal, J., Petit, J.-C., Toulhoat, P., 1994. Clay based materials for engineered barriers. A review. Mater. Res. Soc. Symp. Proc. 353, 221-230.

Pintado, X., Ledesma, A., Lloret, A., 2002. Backanalysis of thermohydraulic bentonite properties from laboratory tests. Eng. Geol. 64 (2-3), 91-115.

Pusch, R., 2001. Experimental Study of the Effect of High Porewater Salinity on the Physical Properties of a Natural Smectitic Clay. SKB Tech. Rep. TR 01-07.

Sánchez, M., Gens, A., 2006. FEBEX Project: Final Report on Thermo-HydroMechanical Modelling, Technical Publication 05-2/2006. Madrid. Enresa.

Sánchez, M., 2004. Thermo-Hydro-Mechanical Coupled Analysis in Low Permeability Media. Ph.D. Thesis, Universitat Politècnica de Catalunya (UPC), Barcelona. $281 \mathrm{pp}$.

Segura, J. Ma., 2008. Coupled HM Analysis using Zero-Thickness Interface Elements with Double Nodes. Tesis de Doctorado-Universidad Politécnica de Catalunya, Barcelona.

Sugita, Y., Chijimatsu, M., Suzuki, H., 2003. Fundamental Properties of Bentonite Pellet for Prototype Repository Project, Advances in Understanding Engineered Clay Barriers, Large Scale Field Tests in Granite: Fundamental Research. Material Behaviour and Laboratory Testing, pp. 293-301.

Tang, A.M., 2005. Effect de la temperature sur le comportement des barrieres de confinement. PhD Thesis, CERMES, ENPC, Paris, France.

Thorsager, P., Börgesson, L., Johannesson, L.-E., Sandén, T., 2002. Canister Retrieval Test, Report on Installation, International Progress Report 02-30.

Van Genuchten, M. Th., 1978. Calculating the Unsaturated Hydraulic Conductivity with a New Closes Form Analytical Model. Research Report 78-WR-08. Dept. of Civil Eng., Pricenton, New Jersey, p. 63.

Villar, M.V., 2002. Thermo-Hydro-Mechanical Characterisation of a Bentonite from Cabo de Gata. A Study Applied to the Use of Bentonite as Sealing Material in High Level Radioactive Waste Repositories. Publicación Técnica ENRESA 01/ 2002, Madrid. 258 pp.

Villar, M.-V., 2003. "AESPOE Hard Rock Laboratory“. CIEMAT Contribution to 2001 Annual Scientific Report. CIEMAT Internal Report CIEMAT/DIAE/54540/2/03.

Villar, M.V., 2005. MX-80 Bentonite, Thermo-Hydro-Mechanical Characterisation Performed at CIEMAT in the Context of the Prototype Project, CIEMAT Technical Report, Madrid, Spain. 